Lipoprotein (a) level in type I diabetes (abstract). Diabetes 1989;38(suppl 2):70A and its correlation with metabolic control (abstract). Diabetes 1990;39 (suppl 1):64A.

31 Cushing GL, Gaubatz JW, Nava ML, Burdick BJ, Bocan TM, Guyton JR, et al. Quantitation and localization of apolipoprotein (a) and B in coronary artery bypass vein grafts resected at re-operation. Arteriosclerosis 1989;

32 Miles LA, Fless GM, Levin EG, Scanu AM, Plow EF. A potential basis for the thrombotic risks associated with lipoprotein (a). Nature 1989;339:301-3.

33 Simon DI, Fless GM, Scanu Am, Loscalzo J. Tissue-type plasminoge activator binds to and is inhibited by lipoprotein (a) (abstract). Circulation 1990;82 (suppl III):599.

34 Andersen AR, Christiansen JS, Andersen JK, Kreiner S, Deckert T. Diabetic nephropathy in type 1 (insulin-dependent) diabetes: an epidemiological study. Diabetologia 1983;25:496-501.
35 Dahl-Jorgensen K, Hanssen KF, Kierulf P, Biøro T, Sandvik L, Aagenæs $\varnothing$ Reduction of urinary albumin excretion after 4 years of continuous subcttaneous insulin infusion in insulin-dependent diabetes mellitus. The Osto Study. Acta Endocrinol (Copenh) 1988:117:19-25.

36 Feldt-Rasmussen B, Mathiesen ER, Deckert T. Effect of two years of strict metabolic control on progression of incipient nephropathy in insulin dependent diabetes. Lancet 1986; ;i: 1300-4.

37 Dahl-Jørgensen K, Hanssen KF, Brinchmann-Hansen O, Kierulf P, Sandvik L. Blood glucose control and progression of diabetic retinopathy and nephropathy. Seven years results from The Oslo Study (abstract). Diabetes 1990;39 (suppl 1):16A.

38 Seaquist ER, Goetz FC, Rich S, Barbosa J. Familial clustering of diabetic kidney disease. Evidence for genetic susceptibility to diabetic nephropathy. N Engl F Med 1989;320:1161-5.

Accepted 24 fune 1991
Cardiovascular Research Unit, Departments of Cardiology and Medicine, University of Edinburgh, Edinburgh EH8 9XF A D Hargreaves, MRCP, lecturer in medicine

R L Logan, MD, overseas senior research fellow

Marjory Thomson, MPHIL, senior dietitian

M F Oliver, FRCP, professor of cardiology

R A Riemersma, PHD, senior lecturer in cardiac

biochemistry

Medical Statistics Unit, Department of

Community Medicine, University of Edinburgh, Edinburgh

R A Elton, PHD, senior lecturer

Correspondence and requests for reprints to: Dr Hargreaves.

BMF 1991;303:678-81

\title{
Total cholesterol, low density lipoprotein cholesterol, and high density lipoprotein cholesterol and coronary heart disease in Scotland $/ 1$
}

\author{
A D Hargreaves, R LLogan, Marjory, Thomson, R A Elton, M F Oliver, R A Riemersma
}

Abstract

Objective-To investigate long term changes in total cholesterol, high density lipoprotein cholesterol, and low density lipoprotein cholesterol concentrations and in measures of other risk factors for coronary heart disease and to assess their importance for the development of coronary heart disease in Scottish men.

Design-Longitudinal study entailing follow up in 1988-9 of men investigated during a study in 1976.

Setting-Edinburgh, Scotland.

Subjects - 107 men from Edinburgh who had taken part in a comparative study of risk factors for heart disease with Swedish men in 1976 when aged 40.

Intervention-The men were invited to attend a follow up clinic in 1988-9 for measurement of cholesterol concentrations and other risk factor measurements. Eighty three attended and 24 refused to or could not attend.

Main outcome measures - Changes in total cholesterol, high density lipoprotein cholesterol, and low density lipoprotein cholesterol concentrations, body weight, weight to height index, prevalence of smoking, and alcohol intake; number of coronary artery disease events.

Results-Mean serum total cholesterol concentration increased over the 12 years mainly due to an increase in the low density lipoprotein cholestero fraction (from $3.53(\mathrm{SD} \mathrm{0.09)}$ to $4.56(0.11) \mathrm{mmol} / \mathrm{l}$ ) despite a reduction in high density lipoprotein cholesterol concentration. Body weight and weight to height index increased. Fewer men smoked more than 15 cigarettes/day in 1988-9 than in 1976. Blood pressure remained stable and fasting triglyceride concentrations did not change. The frequency of corneal arcus doubled. Alcohol consumption decreased significantly. Eleven men developed clinical coronary heart disease. High low density lipoprotein and low high density lipoprotein cholesterol concentrations in 1976, but not total cholesterol concentration, significantly predicted coronary heart disease $(p=0.05)$. Almost all of the men who developed coronary heart disease were smokers $(91 \% v 53 \%, \mathrm{p}<0.05)$.

Conclusion-Over 12 years the lipid profile deteriorated significantly in this healthy cohort of young men. Smoking, a low high density lipoprotein concentration and a raised low density lipoprotein concentration were all associated with coronary heart disease in middle aged Scottish men, whereas there was no association for total cholesterol concentration. The findings have implications for screening programmes.

\section{Introduction}

Mortality from coronary heart disease is not uniform in Europe, either between countries or even within a single country. In Britain, ${ }^{12}$ Scotland and Northern Ireland have the highest mortality from coronary heart disease in middle aged men. The factors causing this geographic variation are not fully understood. Regional differences in standardised mortality ratios for coronary heart disease in Scotland ${ }^{3}$ and in Britain ${ }^{4}$ cannot be explained by variations in the average total cholesterol or high density lipoprotein cholesterol concentration, although variations in smoking and blood pressure provide a partial explanation.

In 1976 a study in Edinburgh and Stockholm gathered cross sectional data and explored reasons for the threefold excess of mortality from coronary heart disease in men aged 40 from Edinburgh. ${ }^{5}$ The men from Edinburgh smoked more cigarettes, had slightly higher blood pressure, were more obese, had a greater insulin response to an oral glucose tolerance test, and had significantly lower adipose linoleic acid concentrations than men aged 40 from Stockholm. In addition they had higher fasting triglyceride and lower high density lipoprotein concentrations. ${ }^{5}$ Serum total cholesterol and low density lipoprotein cholesterol concentrations did not differ between men from the two cities. This cross sectional study suggested, therefore, that raised cholesterol concentration may not be a major contributor to the high mortality from coronary heart disease in Scotland.

In assessing coronary risk factors it is also important to collect longitudinal data. Prospective studies have identified the increased risk of coronary disease associated with raised cholesterol concentration. ${ }^{67}$ The importance of a low high density lipoprotein cholesterol concentration has been controversial. ${ }^{8-10}$ In Britain, the regional heart study initially reported the lack of an independent association between a low high density lipoprotein cholesterol and mortality from coronary heart disease, ${ }^{11}$ but subsequent reports suggest a different interpretation."

We examined whether total cholesterol, high density lipoprotein cholesterol, and low density lipoprotein cholesterol concentrations measured in the 1976 study proved to be significant factors in predicting those men 
from Edinburgh who subsequently developed coronary heart disease. We also recorded the changes in lipid concentrations and clinical measurements in the Scottish cohort of the 1976 study after 12 years.

\section{Methods}

POPULATION SAMPLE

For the initial study names of 210 men aged 40 from Edinburgh had been obtained at random from the General Register Office in 1975. Of these, 33 had no been identifiable on NHS registers in the city, 25 had left the city, four were working on night shifts, and one was ill. The general practitioners of the remaining 147 patients, who were asked if the men could take part in the study, considered nine men unsuitable because of pre-existing cardiovascular disease (one had had a myocardial infarction) and for psychological reasons. Of the 138 asked to participate, 30 did not reply. One asthmatic man who was receiving prednisolone was excluded. The men were first examined between January and June 1976, and 107 (73\%) completed the initial study.

At the end of the study the men had been given general advice concerning prevention of coronary heart disease and their general practitioners were given the principal data-for example, lipid and blood sugar concentrations and blood pressure measurements. The men were unaware of any plans for a follow up study. No active intervention programme was instituted.

FOLLOW UP IN 1988

For the follow up study we identified 102 (95\%) of the men directly through their general practitioner or from records at Lothian Health Board. We established from the electoral register that five men had moved away. Their new addresses were identified from the house sale transaction register (General Register Office of Scotland). Two men could still not be found and it was necessary to trace the spouse or a first degree relative by a similar process. In this way all men were traced.

Two men had died (one of myocardial infarction and one of pulmonary embolism) and five had moved away from Edinburgh - four to England and one to the USA. The remaining 100 men were invited to attend for clinical and laboratory investigations. Seventeen refused or did not attend, giving an overall response rate of $78 \%$ (fig 1 )

\section{MEDICAL HISTORY}

A full medical history was obtained from all men attending the follow up clinic. Any events related to coronary heart disease were identified and their validity confirmed by contacting the men's general practitioners. For the men who did not attend this information was gathered by telephone or letter and again confirmed by the general practitioner if a coronary heart disease

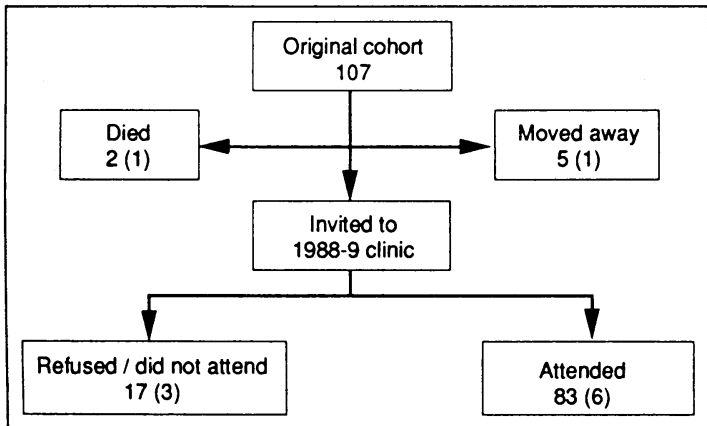

FIG 1 - Protocol for follow up study of men from Edinburgh. Numbers of men who had a coronary heart disease event between $\mathcal{F}$ une 1976 and $\mathcal{F}$ une 1988 are given in brackets event was reported. An event was defined as angina (eight had a previous clinical diagnosis and one had a positive result to a self administered chest pain questionnaire), clinical diagnosis of myocardial infarction $(n=6)$, or coronary artery bypass graft surgery $(n=3)$ (ICD codes 410-413). Some patients fell into more than one category. In all, 11 of the 107 men had had a coronary heart disease event.

\section{CLINICAL PROCEDURES}

All the clinical investigations carried out in 1976 except intravenous fat tolerance and exercise tolerance tests were repeated for the follow up study. The 83 men attended at 8 am on a Tuesday or Wednesday after an overnight fast and were asked not to smoke before their clinic visit. Most men $(n=75)$ attended in June 1988 and eight came in May-June 1989. After their height and weight had been recorded the men relaxed in a semirecumbent position and blood pressure was measured in the right arm after 10 minutes' rest. A sphygmomanometer incorporating a zero muddler had been used to minimise inaccuracies in the original 1976 study but was not used in the follow up study. An intravenous cannula was inserted into an antecubital vein and blood was obtained for serum lipid and lipoprotein analysis. A clinical assessment was then carried out and the London School of Hygiene and Tropical Medicine questionnaire on smoking and angina $^{13}$ was completed. Finally, the subjects were instructed to weigh their food and record what they ate and drank, including alcohol, over seven days. ${ }^{14}$ The data on alcohol is presented here and the full dietary analysis will be the subject of another paper.

\section{LABORATORY PROCEDURES}

Lipid and lipoprotein analyses were carried out within 48 hours of venepuncture by preparative ultracentrifugation. Concentrations of the very low density, low density, and high density lipoprotein fractions of cholesterol and triglyceride were determined by enzymatic analysis with a Cobas Bio centrifugal analyser. ${ }^{15}$ Similar methods had been used in $1976 .{ }^{5}$ The laboratory is standardised according to the World Health Organisation's lipid reference laboratory, Prague, as was the analysing laboratory in Stockholm in 1976.

\section{STATISTICAL METHODS}

Comparisons between corresponding variables in 1976 and in 1988-9 were made by Wilcoxon signed rank or McNemar tests. Comparisons between attenders and non-attenders at the follow up clinic and between subjects with and without coronary heart disease were made by Wilcoxon rank sum tests or $\chi^{2}$ tests with Yates's correction. Confidence intervals for odds ratios were calculated by the method of Thomas. ${ }^{16}$ Cut off points were taken at approximate median values.

\section{Results}

Bias in follow up study-There was no significant difference between attenders and non-attenders at the follow up clinic in concentration of any lipid fraction. Those who attended, however, were more likely to have been non-smokers in 1976 than those who did not attend (table I). The mean alcohol consumption in 1976 of attenders tended to be less, but this was not significant. There were no other biases.

Changing patterns - The mean (SEM) total serum cholesterol concentration increased from $5.47(0.09)$ $\mathrm{mmol} / \mathrm{l}$ to $6.34(0.012) \mathrm{mmol} / \mathrm{l}(\mathrm{p}<0.001)$ over the 12 years, and this was mainly attributable to a $30 \%$ increase in low density lipoprotein cholesterol concentration. A significant reduction in the high density 
lipoprotein cholesterol concentration occurred. Mean triglyceride concentrations remained the same (table II). The increase in low density lipoprotein cholesterol concentration was similar in smokers and non-smokers $(\mathrm{p}=0.80)$. Smoking habit also did not influence the decrease in high density lipoprotein cholesterol concentration $(p=0.56)$. The men became more obese over the 12 years of follow up; both mean weight and mean weight to height index increased (table III). Mean blood pressure did not change. The prevalence of heavy smoking ( $>15$ cigarettes/day) decreased from $41 \%$ to $30 \%(p<0 \cdot 05)$. There was a decrease in daily alcohol consumption.

Lipid concentrations and subsequent coronary heart disease-The 11 men who had had a coronary event over the 12 year follow up period did not have significantly higher mean total cholesterol concentrations in 1976 than the 96 who remained free of coronary heart disease (table IV). However, low density lipoprotein cholesterol concentrations were higher $(3.96(0.21) \mathrm{mmol} / 1$ v $3.50(0.08) \mathrm{mmol} / \mathrm{l}$ $\mathrm{p}=0.05)$ and high density lipoprotein cholesterol concentrations lower $(1 \cdot 11(0.05) \mathrm{mmol} / \mathrm{l} v 1 \cdot 27(0 \cdot 03)$ $\mathrm{mmol} / \mathrm{l} ; \mathrm{p}=0.05)$ in those who developed coronary heart disease. The odds ratio of developing coronary heart disease for men with low density lipoprotein cholesterol concentration above the median value as compared to those with a concentration below the median value was $5 \cdot 6$ (fig 2 ). The serum triglyceride concentration in the men who developed heart disease was slightly but not significantly higher.

Other risk factors-Almost all of the men who developed heart disease were smokers (table IV). Men

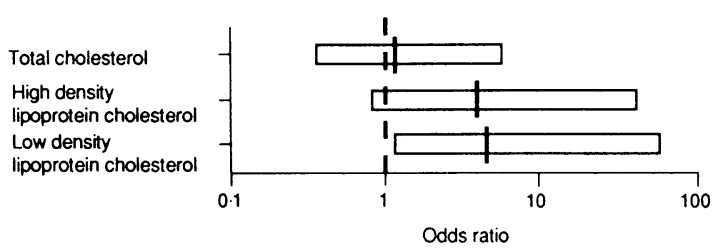

FIG 2-Odds ratios and 95\% confidence intervals for risk of coronary heart disease associated with total cholesterol, low density lipoprotein cholesterol, and high density lipoprotein cholesterol concentrations. Cut off points were taken at approximate median values: $5.5 \mathrm{mmolll}$, $1 \cdot 25 \mathrm{mmol} / \mathrm{l}$, and $3.5 \mathrm{mmol} / \mathrm{l}$ respectively

TABLE I-Assessment of selection bias of attenders at follow up clinic by comparison of mean (SD) baseline clinical and biochemical measurements

\begin{tabular}{|c|c|c|c|}
\hline & $\begin{array}{l}\text { Attenders } \\
(\mathrm{n}=83)\end{array}$ & $\begin{array}{l}\text { Non-attenders } \\
\quad(n=24)^{\star}\end{array}$ & $\mathrm{p}$ Value \\
\hline Total cholesterol $(\mathrm{mmol} / \mathrm{l})$ & $5.47(0.81)$ & $5 \cdot 79(1 \cdot 13)$ & $0 \cdot 14$ \\
\hline Low density lipoprotein cholesterol $(\mathrm{mmol} / \mathrm{l})$ & $3.53(0.77)$ & $3.68(0.87)$ & $0 \cdot 37$ \\
\hline High density lipoprotein cholesterol $(\mathrm{mmol} / \mathrm{l})$ & $1 \cdot 23(0 \cdot 24)$ & $1.33(0 \cdot 28)$ & $0 \cdot 20$ \\
\hline Triglycerides $(\mathrm{mmol} / \mathrm{l})$ & $1.82(1.08)$ & $1.82(0.99)$ & $0 \cdot 98$ \\
\hline Weight $(\mathrm{kg})$ & $75 \cdot 5(8 \cdot 8)$ & $74 \cdot 8(13 \cdot 3)$ & $0 \cdot 33$ \\
\hline Height $(\mathrm{cm})$ & $173.6(6.0)$ & $172 \cdot 3 \quad(7 \cdot 7)$ & $0 \cdot 25$ \\
\hline Weight to height index $\left(\mathrm{kg} / \mathrm{m}^{2}\right)$ & $25 \cdot 0(2 \cdot 5)$ & $25 \cdot 1 \quad(3 \cdot 2)$ & 0.91 \\
\hline Systolic blood pressure $(\mathrm{mm} \mathrm{Hg}$ ) & $137 \quad(14)$ & $138 \quad(18)$ & 0.99 \\
\hline Diastolic blood pressure $(\mathrm{mm} \mathrm{Hg})$ & $88 \quad(11)$ & (12) & $0 \cdot 91$ \\
\hline Alcohol intake (g/day) & $38 \quad(43)$ & $47 \quad(38)$ & $0 \cdot 39$ \\
\hline Prevalence of smoking (\%) & 50 & 79 & 0.02 \\
\hline
\end{tabular}

^Includes those who had died, those who refused to attend, those who had moved away, and those who did not attend for other reasons.

TABLE II-Mean (SEM) serum lipid and lipoprotein concentrations in 1976 and 1988-9 in men from Edinburgh $(n=83)$ who attended follow up clinic

\begin{tabular}{lccc}
\hline Serum concentration $(\mathrm{mmol} / \mathrm{l})$ & 1976 & $1988-9$ & $\begin{array}{c}95 \% \\
\text { Confidence interval } \\
\text { for mean change }\end{array}$ \\
\hline Total cholesterol & $5 \cdot 47(0 \cdot 09)$ & $6 \cdot 34(0 \cdot 12)^{\star \star \star}$ & $+0 \cdot 70$ to $+1 \cdot 05$ \\
Very low density lipoprotein cholesterol & $0 \cdot 71(0 \cdot 05)$ & $0 \cdot 70(0 \cdot 06)$ & $-0 \cdot 11$ to $+0 \cdot 09$ \\
Low density lipoprotein cholesterol & $3 \cdot 53(0 \cdot 09)$ & $4 \cdot 56(0 \cdot 11)^{\star \star \star}$ & $+0 \cdot 88$ to $+1 \cdot 20$ \\
High density lipoprotein cholesterol & $1 \cdot 23(0 \cdot 03)$ & $1 \cdot 16(0 \cdot 04)^{\star \star}$ & $-0 \cdot 12$ to $-0 \cdot 02$ \\
Total triglyceride & $1 \cdot 82(0 \cdot 12)$ & $1 \cdot 83(0 \cdot 12)$ & $-0 \cdot 22$ to $+0 \cdot 24$ \\
Very low density lipoprotein triglyceride & $1 \cdot 20(0 \cdot 11)$ & $1 \cdot 23(0 \cdot 10)$ & $-0 \cdot 06$ to $+0 \cdot 13$ \\
\hline
\end{tabular}

$\star \star \mathrm{p}<0.01 ; \star \star \star \mathrm{p}<0.001$ who developed coronary heart disease were more obese (according to the weight to height index or thickness of abdominal skinfolds) in 1976 than the 96 men who remained free of coronary heart disease. Diastolic blood pressure was on average $5 \mathrm{~mm} \mathrm{Hg}$ higher in those who had a coronary event, but this was not significant; systolic blood pressure differed even less (results not shown).

\section{Discussion}

\section{LONGITUDINAL SURVEY}

The changes that occurred over the 12 years in this study should be considered relative to two facts. One is that the men were initially healthy and all were aged 40 , and the other is that no intervention programme was initiated. There was an increase of $29 \%$ in mean low density lipoprotein cholesterol concentration. Total cholesterol concentration also increased, despite a reduction in high density lipoprotein cholesterol concentration of $6 \%$. Thus the mean (SD) ratio of low density lipoprotein cholesterol to high density lipoprotein cholesterol increased from $3.00(0 \cdot 11)$ to $4 \cdot 17$ $(0 \cdot 13)(\mathrm{p}<0 \cdot 001)$.

One longitudinal study showed an increase in total cholesterol and low density lipoprotein cholesterol concentrations with time ${ }^{17}$ yet others showed little or no overall change. ${ }^{18-20}$ The increase in serum total cholesterol concentration and, presumably, in low density lipoprotein cholesterol concentration was more pronounced than cross sectional data would have predicted for the age range of our subjects. ${ }^{21}$ The rise in total cholesterol or low density lipoprotein cholesterol may be secondary to weight gain. ${ }^{18} 19$ Indeed, in our population the rise in total cholesterol was related to the increase in body weight $(\mathrm{r}=0 \cdot 35, \mathrm{p}<0 \cdot 01)$.

High density lipoprotein cholesterol concentration is generally assumed either to be stable or to increase in white males after puberty. ${ }^{22}$ In Scotland high density lipoprotein cholesterol concentration did not vary with age over the range 26-64 years. ${ }^{21}$ But longitudinal studies have shown small decreases in high density lipoprotein cholesterol concentration with age, ${ }^{1820}$ and these could be partly explained by a decrease in alcohol consumption and an increase in body weight. ${ }^{18}$ In our cohort there was a significant fall in high density lipoprotein concentrations. Whether the absolute concentrations were high or low depended on the source of the data used for comparison..$^{202}$ Alcohol consumption decreased over the 12 years, but there was no significant relation between the fall in high density lipoprotein cholesterol concentration and fall in alcohol consumption $(r=0.06)$. Nor was the change in high density lipoprotein concentration related to that in weight $(\mathrm{r}=0.002)$.

The prevalence of smoking was lower after 12 years. Surprisingly, mean blood pressure did not change, but this could be due to the fact that during the intervening period some men had received long term antihypertensive treatment from their general practitioners.

The pronounced increase in low density lipoprotein cholesterol concentration and the ratio of low density lipoprotein cholesterol to high density lipoprotein cholesterol took place in men at a time in their lives when cholesterol concentrations are expected to remain stable. Initially these men may have been healthier than the average man from Edinburgh as their initial mean total cholesterol concentration was considerably lower than expected. ${ }^{21} 23$ The increase is therefore of particular concern in an era of expanding health education. The implication for health screening is that a lipoprotein profile not normally associated with coronary heart disease may deteriorate significantly over a number of years. 


\begin{tabular}{|c|c|c|c|}
\hline & 1976 & $1988-9$ & $\begin{array}{c}95 \% \\
\text { Confidence interval } \\
\text { for mean change }\end{array}$ \\
\hline Weight $(\mathrm{kg})$ & $75 \cdot 5(1 \cdot 0)$ & $78 \cdot 0(1 \cdot 1)^{\star \star \star}$ & $+1 \cdot 2$ to $+3 \cdot 7$ \\
\hline Height $(\mathrm{cm})$ & $173 \cdot 6(0 \cdot 7)$ & $173 \cdot 3(0 \cdot 8)$ & $-1 \cdot 1$ to $+0 \cdot 5$ \\
\hline Weight to height index $\left(\mathrm{kg} / \mathrm{m}^{2}\right)$ & $25 \cdot 0(0 \cdot 3)$ & $26 \cdot 0(0 \cdot 4)^{\star \star \star}$ & $+0 \cdot 4$ to $+1 \cdot 6$ \\
\hline Systolic blood pressure ( $\mathrm{mm} \mathrm{Hg}$ ) & $137 \quad(2)$ & 138 (2) & -4 to +5 \\
\hline Diastolic blood pressure $(\mathrm{mm} \mathrm{Hg})$ & $88 \quad(1)$ & $90 \quad(2)$ & -2 to +6 \\
\hline Prevalence of corneal arcus $(\%)$ & 26 & $49^{\star \star \star}$ & +12 to +28 \\
\hline Prevalence of smoking $(\%)$ & 50 & 39 & -18 to 0 \\
\hline Prevalence of smoking $>15$ cigarettes/day $(\%)$ & 41 & $30^{\star}$ & -19 to -1 \\
\hline Alcohol intake (g/day) & $40 \quad(5)$ & $28(4)^{\star \star}$ & -21 to -3 \\
\hline
\end{tabular}

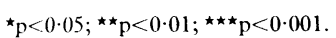

tAnalysis performed only on attenders at follow up clinic.

TABLE IV-Comparison of mean (SEM) baseline lipid concentrations and other risk factor measurements in 1976 in men from Edinburgh who did or did not develop coronary heart disease over 12 years from 1976 to $1988-9$

\begin{tabular}{|c|c|c|c|}
\hline & $\begin{array}{c}\text { Men without } \\
\text { coronary heart disease } \\
(\mathrm{n}=96)\end{array}$ & $\begin{array}{c}\text { Men with coronary } \\
\text { heart disease } \\
(\mathrm{n}=11)\end{array}$ & p Value \\
\hline Total cholesterol $(\mathrm{mmol} / \mathrm{l})$ & $5 \cdot 50(0 \cdot 09)$ & $5 \cdot 89(0 \cdot 22)$ & $0 \cdot 17$ \\
\hline Low density lipoprotein cholesterol $(\mathrm{mmol} / \mathrm{l})$ & $3.50(0.08)$ & $3.96(0.21)$ & 0.05 \\
\hline High density lipoprotein cholesterol $(\mathrm{mmol} / \mathrm{l})$ & $1 \cdot 27(0.03)$ & $1 \cdot 11(0.05)$ & 0.05 \\
\hline Total triglyceride $(\mathrm{mmol} / \mathrm{l})$ & $1.73(0 \cdot 11)$ & $1.99(0 \cdot 30)$ & 0.32 \\
\hline Weight to height index $\left(\mathrm{kg} / \mathrm{m}^{\prime}\right)$ & $24 \cdot 9(0 \cdot 3)$ & $26 \cdot 7(0 \cdot 8)$ & $0 \cdot 02$ \\
\hline Diastolic blood pressure $(\mathrm{mm} \mathrm{Hg})$ & $88 \quad$ (1) & $93 \quad(3)$ & $0 \cdot 11$ \\
\hline Prevalence of smoking $(\%)$ & 53 & 91 & $0 \cdot 04$ \\
\hline Alcohol intake ( $\mathrm{g} /$ day) & $37 \quad(4)$ & $48 \quad(17)$ & 0.93 \\
\hline
\end{tabular}

\section{DEVELOPMENT OF CORONARY HEART DISEASE}

Over the 12 years, 11 men developed coronary heart disease, giving an approximate annual incidence of $0 \cdot 9 \%$. Serum total cholesterol concentration did not relate to subsequent coronary heart disease, but a low high density lipoprotein cholesterol concentration was a risk factor. The predictive role of a low density lipoprotein cholesterol concentration was confirmed in this cohort, with an odds ratio of $5 \cdot 6$ (fig 2). The $95 \%$ confidence interval of the odds ratio (1.06 to 55) emphasises, however, the low power of this study to estimate accurately the strength of possible risk factors. It is not possible to say whether a low high density lipoprotein concentration or a high low density lipoprotein cholesterol concentration is the more important factor, as neither predicts heart disease when adjusted for the other; nevertheless, the study confirms the importance of both in Scotland as risk factors for heart disease. Neither systolic nor diastolic blood pressure at baseline discriminated those who subsequently developed heart disease.

Recent data from the regional heart study ${ }^{12}$ suggest that a low high density lipoprotein cholesterol concentration is associated with an increased risk of heart disease independent of total cholesterol concentration, in contrast to an earlier report." The association between a raised non-high density lipoprotein cholesterol concentration (reflecting low density lipoprotein cholesterol concentrations) or a low high density lipoprotein cholesterol concentration and coronary heart disease is in agreement with several longitudinal studies. Thus the cross sectional data ${ }^{5123}$ in which differences in mortality from coronary heart disease could not be explained by gradients in average total cholesterol or low density lipoprotein cholesterol, or both, may be misleading.

Almost all men who developed coronary heart disease were smokers and the estimated odds ratio for heart disease in those who smoked in 1976 as compared with those who did not was $8 \cdot 8$. The odds ratio for heart disease in those with a weight to height ratio of greater than $25 \mathrm{~kg} / \mathrm{m}^{2}$ as compared with those whose ratio was below this cut off was $5 \cdot 3(95 \%$ confidence interval 1.0 to $52 \cdot 4$ )

In conclusion, this 12 year follow up study of a small cohort of 107, 40 year old men has limited power in predicting future coronary heart disease but shows that both a raised low density lipoprotein concentration and a low high density lipoprotein cholesterol concentration are important for the development of coronary heart disease in Scottish men.

This study was supported by a grant from the Scottish Chest Heart and Stroke Association. RLL received an overseas research fellowship of the New Zealand Heart Foundation and the Wellington School of Medicine, Otago University. We thank Fiona Paton, Alison Temple, Mary Walker, and Martin Williams for expert help and Christina Anderson and Inez Johnstone for their secretarial help.

I Elford J, Phillips AN, Thomson AG, Shaper AG. Migration and geographic variations in ischaemic heart disease in Great Britain. Lancet 1989;i:343-6. 2 Principal Investigators of the Monica Project. WHO Monica project geographic variation in mortality from cardiovascular diseases-baselin data on selected population characteristics and cardiovascular mortality. World Health Stat $Q$ 1987;40:171-84

3 Tunstall-Pedoe H, Smith WCS, Crombie IK, Tavendale R. Coronary risk factor and lifestyle variation across Scotland: results from the Scottish heart health study. Scot Med f 1989;34:556-60.

4 Shaper AG, Pocock SJ, Walker M, Cohen NM, Wale CJ, Thomson AG. British regional heart study: cardiovascular risk factors in middle-aged men in 24 towns. BMF 1981;283:179-86.

5 Logan RL, Riemersma RA, Thomson M, Oliver MF, Olsson AG, Walldins G, et al. Risk factors for ischaemic heart disease in normal men aged 40. Lancet $1978 ; i: 949-55$

6 Kannel W/B, Castelli WP, Gordon T. Cholesterol in the prediction of atherosclerotic disease. New perspectives based on the Framingham study. Ann Intern Med 1979;90:85-91.

7 Stamler J, Wentworth D, Neaton JI). Is relationship between serum cholesterol and risk of premature death from coronary heart disease cholesterol and risk of premature death from

8 Miller NE, Thelle DS, Forde OH, Miøs OD. The Tromsø heart study. High density lipoprotein cholesterol and coronary heart disease; a prospective density lipoprotein cholesterol and coron

9 Gordon T, Castelli WP, Hjortland MC, Kannel WB, Dawher TR. High density lipoprotein cholesterol as a protective factor against coronary hear disease. The Framingham study. Am $f$ Med 1977;62:707-14

10 Keys A, Karvonen MJ, Punsar S, Menotti A, Fidanza F, Farchi G. HDI serum cholesterol and 24-year mortality of men in Finland. Int 7 Epidemiol 1984;13:428-35

11 Pocock SJ, Shaper AG, Phillips AN, Walker M, Whitehead TP. High density lipoprotein cholesterol is not a major risk factor for ischaemic heart disease in British men. BMF 1986;292:515-9.

12 Pocock SJ, Shaper AG, Phillips AN. Concentrations of high density lipoprotein cholesterol, triglycerides, and total cholesterol in ischaemic heart disease. BMF 1989;298:998-1002.

13 Rose G, McCartney P, Reid DD. Self administration of questionnaire on ches pain and intermittent claudication. British fournal of Preventive and Social Medicine 1977;31:42-8

14 Thomson M, Logan RL, Sharman M, Lockerbie L, Riemersma RA Oliver MF. Dietary survey in 40-year old Edinburgh men. Hum Nutr Appl Nutr 1982.36A:272-80.

15 Wood DA, Riemersma RA, Butler S, Thomson M, Macintvre C, Elton RA. Linoleic and eicosapentaenoic acids in adipose tissue and platelets and risk of coronary heart disease. Lancel 1987; : $177-83$.

16 Thomas DG. Exact confidence limits for the odds ratio in a $2 \times 2$ table. Journal of the Royal Statistical Society / R/ 1971;20:105-10.

17 Clark DA, Allen MF, Wilson FH. Longitudinal study of serum lipids. 12-year report. Am f Clin Nutr 1967;20:743-52.

18 Criqui MH, Frankville DD, Barratt-Conor E, Klauber MR, Holdbrook MJ, Turner JD. Change and correlates of change in high and low density lipoprotein cholesterol after 6 years: a prospective study. Am $\mathcal{F}$ Epidemiol 1983;118:52-9.

19 Kromhout D. Body weight, diet, and serum cholesterol in 871 middle-aged men during 10 years of follow-up (the Zutphen study). Am F (lin Nutr 1983;38:591-8.

20 Castelli WP, Garrison RJ, Wilson PWF, Abbott RD, Kalousdian S, Kannel WB. Incidence of coronary heart disease and lipoprotein levels. The Framingham study. FAMA 1986;256:2835-8.

21 Smith WCS, Tunstall-Pedoe H, Crombie IK, Tavendale R. Concomitants of excess coronary deaths-major risk factors and lifestyle findings from 10359 men and women in the Scotrish heart health study. Scot Med 1989;34:550-5.

22 Gidez LI, Eder HA. The clinical significance of plasma high-density lipoproteins. In: Miller NE, Miller GJ, eds. Clinical and metabolic aspects of hiph-density. Lipoprotins Am

23 Oliver MF, Nimmo IA, Cooke M, Carlson LA, Olsson AG. Ischaemic hear disease and associated risk factors in 40 year old men in Edinburgh and Stockholm. Eur f Clin Invest 1975; 5:507-14.

(Accepted 4 fuly 1991 , 